\title{
Exploration on the Spatial Assembling Pattern of Contemporary Rural Settlements Based on GIS --- Taking Diqing Tibetan Autonomous Prefecture as an Example
}

\author{
Qi Liu'1,a and Yiwei Zhang ${ }^{2}$ \\ ${ }^{1}$ Gold Mantis School of architecture, Soochow University, No. 199 Ren Ai Road, Wu Zhong District, Jiangsu City, Suzhou Province, China \\ ${ }^{2}$ Ludong University; Room 232, No.49, Hongqi Mid-road 186, Zhifu District, Yantai, Shandong Province, China
}

\begin{abstract}
Rural settlements of China are in the era of rapid information development, experiencing revolutionary changes and cultural breakthroughs. This article takes the main rural settlements in Diqing as examples and uses GIS technology as the main method, analyses spatial distribution and assembling characteristics of rural settlements. Based on this, the article extracts the spatial assembling pattern of Diqing rural settlements. Take the topography, rivers, roads and other factors, this article analyzes the causes of the spatial distribution pattern of contemporary rural settlements. The article argues that it has a great theoretical and practical significance to study the spatial pattern of rural settlements, and points out the necessity of using modern GIS technology in the rural settlement research. This method cannot be only maximum the precise analytical ability of contemporary traditional rural settlement space, but also better serve the adjustment, control and optimization design of contemporary settlements.
\end{abstract}

\section{Introduction}

Diqing Prefecture is located in the hinterland of the Hengduan Mountains, forming not only the special natural landform, but also the heart of three parallel rivers. Due to the common effects of geomorphology and climate, three ecological environments are formed in the vertical distribution: high and cold regions (2800 6740 meters), mountain areas (2200 2800 meters) and valley regions (1486 2200 meters). This is the result of longterm human production activities and the surrounding environment. Under the drive of different material structure and location environment, there are obvious differences in the spatial distribution characteristics of rural settlements. The development of traditional rural settlements is facing many difficulties. We should introduce the interdisciplinary ${ }^{[1]}$ system and research methods to solve the contemporary contradictions.

\section{The spatial distribution pattern of rural settlements}

According to the different terrain parts of the settlement and the size of the ground slope, this article divides the settlement of Diqing Prefecture into four types of patterns: River Valley Settlement (topographic slope $<5$ ), Level Ground Settlement (topographic slope $<5$ degree), Mountain Gentle Slope Settlement (topographic slope 5 25 degree) and Mountain Steep Slope Settlement (topographic slope $>25$ degrees) (Figure 1).

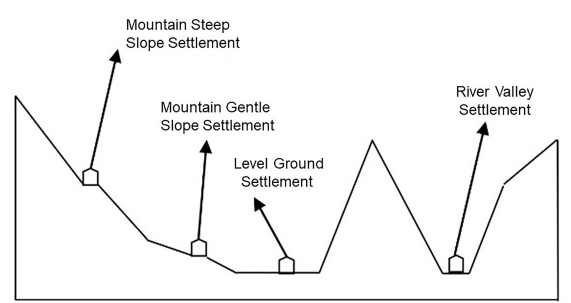

Figure 1. The spatial distribution pattern of rural settlements.

\subsection{River valley settlement}

This kind of settlement is located on both sides of the river with the very gentle valley flat or terrace. Restricted by the terrain conditions, it has the characteristics of small scale and small size. Because of the high mountains and valleys, the valley is widely distributed (Figure 2).

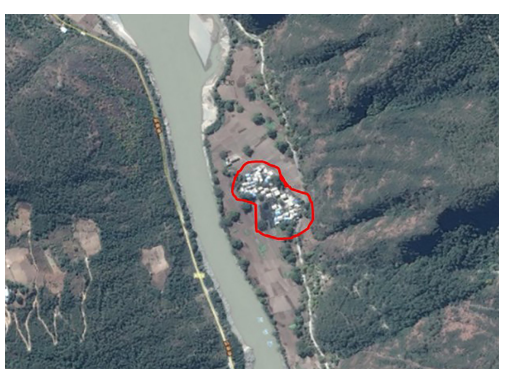

Figure 2. River valley settlement.

a Corresponding author: 450621929@qq.com 


\subsection{Level ground settlement}

This type of low and small landform is also known as "Dam" by Yunnan people. River swirling reaches the most easily formed valley flat, and eventually forms a larger valley flat terrace (Figure 3 ).

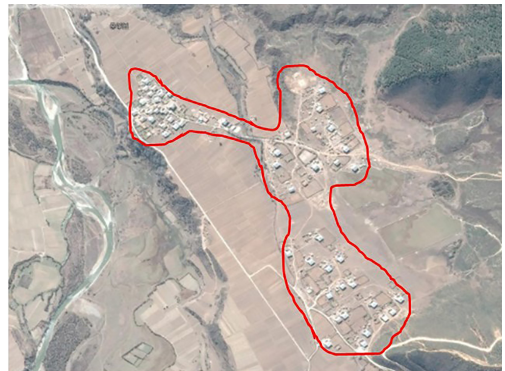

Figure 3. Level ground settlement.

\subsection{Mountain gentle slope settlement}

In the altitude of the river above $150 \mathrm{~m}$ to $200 \mathrm{~m}$, there is a relatively gentle slope in the mountain area, which is the most important rural settlement area in the basin, and the main type of settlement in Diqing as well (Figure 4).

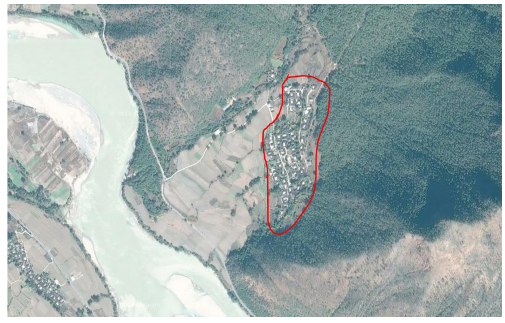

Figure 4. Mountain gentle slope settlement.

\subsection{Mountain steep slope settlement}

This typical alpine zone with relatively steep slope is an important rural settlement area in the basin. The settlement is far away from the river or valley, the altitude is relatively high, and the location is higher in the three-dimensional structure of the settlement (Figure 5).

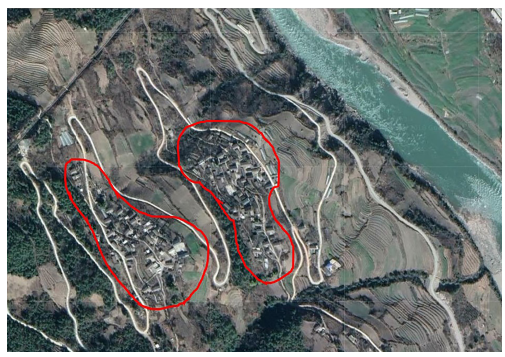

Figure 5. Mountain steep slope settlement.

\section{Spatial agglomeration characteristics of rural settlements}

Using ArcGIS for density mapping of rural settlements in Diqing County, there are three ways to express density, namely kernel density, point density and linear density. In this article, the kernel density estimation method is used to analyze the spatial agglomeration characteristics of rural settlements in Diqing county (Figure 6).

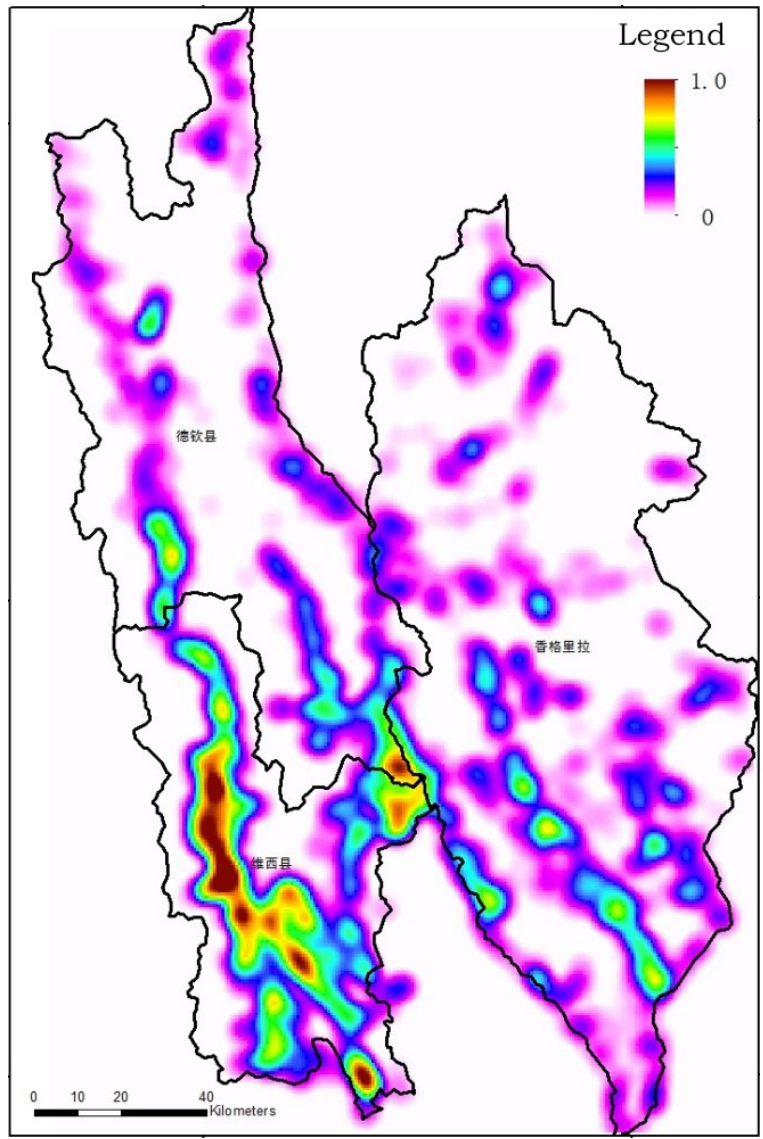

Figure 6. The distribution of kernel density in rural settlements in Diqing.

\subsection{The distribution of settlement has obvious characteristics of banded agglomeration}

The results are as follows: three density belts in Deqin county are from the west to the East, followed by the Lancang River density belt, the Zhu Balong River density belt and the Jinsha River high density belt. Wei Xi county is: Lancang river high density belt, Napu River density belt and Yongchun River density belt. Shangri-La is: Wengshui River density belt and Zhongdian River density belt. The zonal distribution of kernel density indicates that the distribution of settlements has obviously banded characteristics in space. From north to south, the bandwidth is widening.

\subsection{The value of kernel density has obvious regional differences}

According to the distribution map of the kernel density of the settlements, the first result is that the density of the north is low and the density of the south is large, that is, the north is sparse and the south is dense. The second result is that the density of the East is small and the density of the west is large. Third, there are obvious differences in distribution in Deqin County, Wei Xi 
county and Shangri-La City, and the distribution is uneven. That is: Wei Xi county $>$ from Shangri-La City $>$ Deqin County. Wei Xi county is the highest density area in Diqing Prefecture, indicating that Wei Xi county is the most widely distributed and concentrated area of rural settlements.

\subsection{Settlement distribution has two distinct centralization cores}

The distribution of the settlements in the study area has obvious north-south zonal distribution, and there are two distinct centralization cores. The first core area is the Lancang River in the midwestern of Wei Xi county. The core density is $1.06 \mathrm{~d} / \mathrm{km} 2$. The second core area is at the junction of Deqin County and Wei Xi county on the West Bank of the Jinsha River. These two centralization cores constitute the thermal region of the distribution of rural settlements in Diqing Prefecture.

\section{The pattern of rural settlement space agglomeration}

\subsection{Pattern 1: multiple lines, near parallel banded}

The key combination of this model is multi axis + parallel + North-South + zonal distribution. On the macro-scale, the formation of this pattern is closely related to the control of the Hengduan Mountains. The pattern formed with the pattern of the river network in Diqing state is extremely fit, which is also unique in the whole country. The pattern formed is corresponding to the pattern of Diqing river network, which is unique throughout the country.

\subsection{Pattern 2: comb-like structure}

According to the spatial distribution, the special terrain conditions make the vertical core distribution belt and the second level distribution belt form a vertical linear distribution combination, which is the comb-like structure pattern. It can also be called the "T-type" structure pattern. This pattern emphasizes the relationship between kernel density zones.

\subsection{Pattern 3: high-cold with depopulated zone}

According to the results of GIS spatial analysis, the number of settlements began to decline from the altitude of 2800 meters. The number of settlements above 3400 meters above sea level amounts to 154 , accounting for $6 \%$ of the total settlement, and the settlement density is less than 0.02 per square kilometer. As a result, the above $3400 \mathrm{~m}$ is almost depopulated zone. The area of no settlement area is about $13118 \mathrm{~km}^{2}$, accounting for $57 \%$ of the total area of the total Diqing area (according to the height belt statistics).

\section{The cause of the spatial agglomeration of rural settlements}

The factors that influence the spatial agglomeration of rural settlements include both internal and social factors as well as natural factors. ${ }^{[2]}$ Among them, the main driving factor in the evolution of rural settlement spatial structure is from the humanities and social factors, and the basis of the formation and development of the rural settlement space structure is the natural factor. The research shows that the natural factors affecting the spatial structure of rural settlements in Diqing mainly include two aspects: terrain conditions and hydrological conditions. The primary constraints on the location, layout, scale and type of rural settlements are topography and hydrological conditions. This article only discusses the influence of natural factors on the spatial agglomeration pattern of rural settlements.

\subsection{The influence of terrain on spatial agglomeration of rural settlements}

The main factor affecting the agricultural production and life of the rural settlement residents is the topography of the settlement, which is the main factor in the formation of the spatial distribution pattern of the rural settlements. [3] Topographic conditions mainly include altitude, ground slope and surface cutting degree, etc. Among them, the limitation of altitude and slope affects the distribution, scale, form and development direction of rural settlement, and also has a great influence on the location of settlement.

\subsubsection{The influence of altitude on spatial agglomeration of rural settlements}

Altitude limits the direction of settlement agglomeration and makes settlements gather at low altitude valley areas, so many settlements have the characteristics of the distribution along the river, because the valley is the lowest area of the local altitude. By overlaying the altitude distribution diagram of rural settlements and the classification map (Figure 7). Statistical analysis data such as the number of settlements in various elevation zones are obtained (Figure 8).

Generally, the smaller the number of settlements, the higher of the altitude. However, the influence of the same altitude on the distribution of settlements is different. With the increase in altitude, the distribution density of rural settlements (the number of settlements in the unit area) gradually decreased. In other words, the higher the altitude is, the more dispersed rural settlements are. Over $3400 \mathrm{~m}$, the total number of settlements was 154, accounting for $6 \%$ of the total settlements, and the settlement density was less than 0.02 per square kilometer. Therefore, the above $3400 \mathrm{~m}$ is almost depopulated zone, which is due to the environmental conditions formed by the external natural factors, thus affecting the comfort of the settlement environment, and finally reflecting on the spatial distribution. 


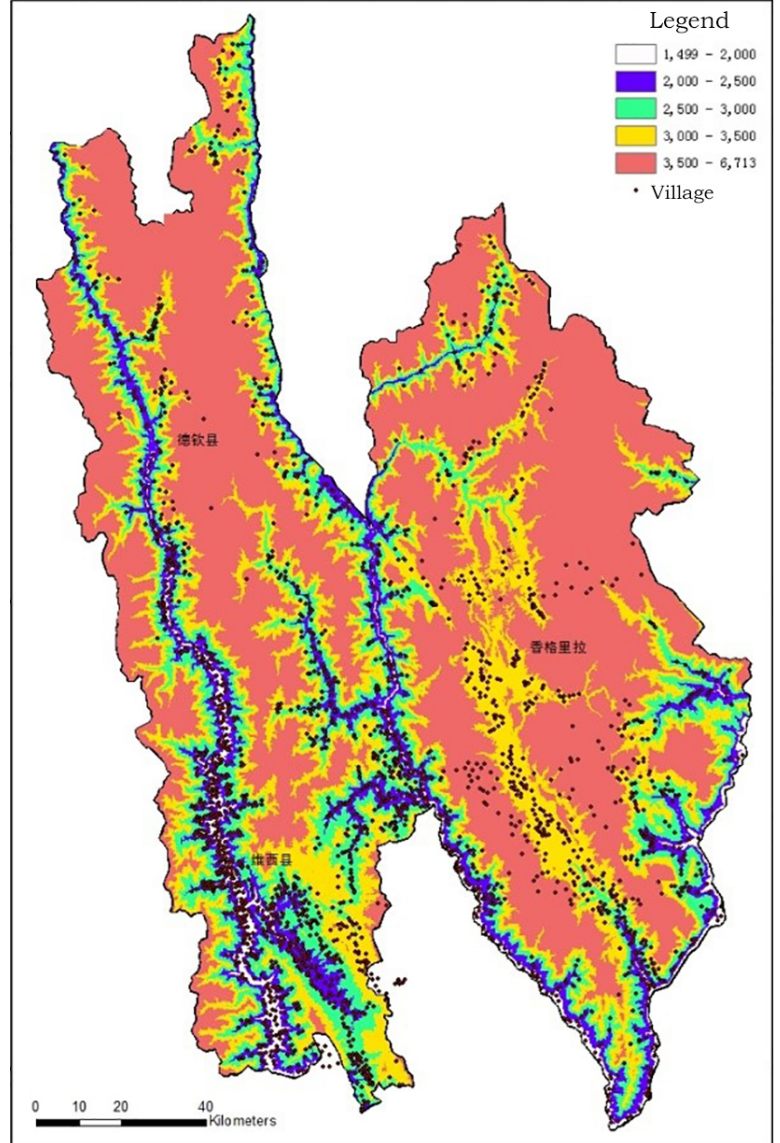

Figure 7. Settlement distribution and DEM superposition diagram.

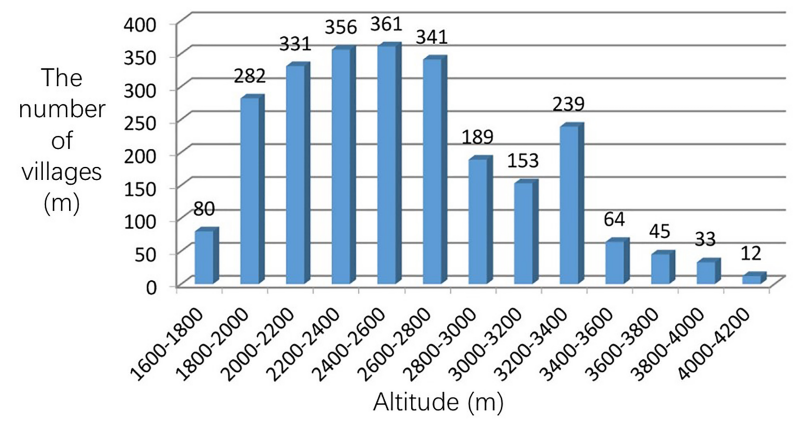

Figure 8. Rural settlement distribution map at different altitudes.

\subsubsection{The influence of slope on spatial agglomeration of rural settlements}

Similar to altitude, there are great differences in the distribution of settlements in different areas at the same altitude. The maximum slope of the rural settlements in Diqing county is 44.9 degrees, that is, there is no settlement distribution above 44.9 degrees. The research area belongs to the mountain valley landform area, the terrace and dam land on both sides of the river valley, because of the small slope and the location near the water source and road, the production and living conditions are relatively superior, thus the settlement density is large and the quantity is quite a few. However, there are still many settlements in gentle slopes, slopes and steep slopes, the cause is multifactorial. Firstly, the study area belongs to the topography of the alpine canyon. Compared with the area with a small slope, the area is very limited. Secondly, there are abundant land resources in different slope area, which is an important agricultural and husbandry zone in Diqing Prefecture. Finally, the distribution of settlements is related to the traditional settlement layout concept in minority areas.

\subsubsection{Influence of slope direction on spatial agglomeration of rural settlements}

From the perspective of production and life, sunny slope is more suitable for human settlement. Thus settlement location usually chooses a sunny slope. However, for this study area, the influence of slope direction on settlement distribution is different (Figure 9). There are 390 settlements in the southwest direction, with a settlement density of $0.135 \mathrm{~km} / \mathrm{d}$. There are 654 settlements in three directions: north, west and northeast, accounting for $26 \%$ of the total settlement. There are 1084 settlements in three directions: South, southwest and Southeast, accounting for $43 \%$ of the total settlement. As a whole, the location and layout of rural settlements in the study area is dominated by the south, followed by east and west, and the north is the least and the smallest in the settlement.

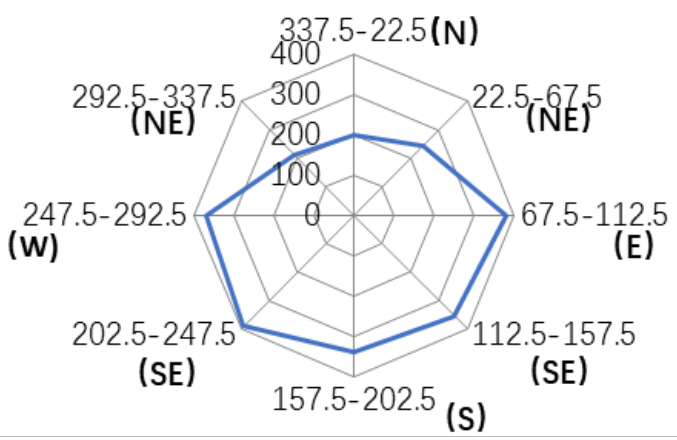

Figure 9. Rural settlement distribution number at different slope.

\subsection{The influence of rivers on spatial agglomeration of rural settlements}

The results of river buffer analysis showed that the number of rural settlements showed significant differences in different buffer zones. The number of settlements decreased sharply with the increase of distance from rivers, and showed an exponential decline pattern. By analyzing the buffer zone of all rivers, the proportion of rural settlements is about $68 \%$ in the area within $1000 \mathrm{~m}$ from the river, while the number of settlements in the $1000-2000 \mathrm{~m}$ buffer zone accounts for only $18 \%$ of the total settlement. It can be seen that the distribution pattern of the settlements is a typical type of spool type settlement, which is distributed along both sides of the big river and its tributaries. 


\subsection{The influence of road on spatial agglomeration of rural settlements}

The results of road buffer analysis show that the more the settlement and the higher the density, the closer to the road. On the contrary, the less the number of settlements and the lower the density, the farther from the road. This shows that the spatial agglomeration of rural settlements is a linear pattern along the road, showing strong road directivity. The unique terrain and geographic conditions of Diqing state make the most of the main roads distributed along the valley, and the distribution of roads is often highly consistent with the distribution of rivers. The influence of river on settlement belongs to the influence of natural factors, and the influence of Road on the distribution of settlement belongs to the influence of human factors. Although the influence of the two factors are similarity, the influence of the river is more important in this study area, and the influence of the road is subordinate.

\section{Conclusion}

Diqing Prefecture is located in the three provinces of Yunnan, Sichuan and Tibet. It is a national area with high altitude, fragile ecological environment and underdeveloped areas. Under the condition of topography, the distribution of rural settlements has obvious vertical differentiation, and shows a distinct three-dimensional distribution pattern. In the development of the rural settlement in the region, the main problems existing in the majority of villages are not planning or planning the low starting point, which leads to the random construction of the houses, the lack of standard and rational layout, which has caused the waste of resource. At the same time, the loss of resources will gradually lead to changes in people's aesthetic values and values. ${ }^{[4]}$

According to the research data, the problems existing in the development of rural areas in China are small scale and scattered layout. It has led to major problems such as low efficiency, high cost and weak practicability in the construction of infrastructure. Even in the relatively remote villages, the problems of low quality traffic conditions, such as narrow road surface and poor road condition are very prominent. It is difficult to set up water pipes for living and installation of modern electronic equipment lines. Eventually, A single perspective and research method can not achieve the purpose of sustainable development, and the planning technique is lagging behind, resulting in a one-sided and chaotic village and town planning system, which can not effectively use and excavate the basic resources of humanity, history, mountain and water.

The era of big data has arrived. The study shows that the study of the rural settlement in Diqing Tibetan Autonomous Prefecture based on the GIS method is of theoretical and practical significance to the implementation of the contemporary urban and rural development strategy. At the same time, it is necessary to introduce modern GIS technology in modern rural settlement research and development planning. On the one hand, effective data can be obtained intuitively and scientifically, and on the other hand, data can be used to carry out effective statistical analysis to feed back to the planning protection, inheritance and utilization of rural settlements. At the same time, it is also significant to create the contemporary design database.

\section{References}

1. Liangyong $\mathrm{Wu}$. Introduction to Science of Human Settlements, China Architecture \& Building Press, 17 (2001).

2. McKenzie P, Cooper A, McCann T, etal. The ecological impact of rural building on habitats in an agricultural landscape, Landscape and Urban Planning, 3, 262-268 (2011).

3. Tianrong Zhang, Xiaolin Zhang, Chuanwu Li. Spatial pattern and influence factors of rural settlements in Zhenjiang Hilly area, Resources and Environment in the Yangtze Basin, 3, 262-268 (2011).

4. Thomlinson J R, Rivera L Y. Suburban growth in Luquillo, Puerto Rico: some consequences of development on natural and semi-natural systems, Landscape \& Urban Planning, 1, 15-23 (2000). 